\title{
CAN WE SURVIVE WITH FOSSIL FUELS?
}

\section{Ioana Ionel*, Ramon Mihai Balogh, Delia Gabriela Calinoiu, Claudiu Ion Ungureanu}

\author{
Politehnica University, Timisoara, 300006, Romania \\ * corresponding author: ioana.ionel@upt.ro
}

\begin{abstract}
Fossil fuels are known as representing by far the majority of world-wide power today, they still are an abundant resource, even fundamentally limited, but continuously new reservoirs are still found They are blamed for not being clean and polluting the environment, generating irreversible effects such as climate change, human crises for the control of resources (such as oil and gas), depletion of natural resources, destroying eco-systems. But still energy demand is on continuous raise and not only because the population is growing, especially in developing or less developed countries from Asia and Africa, but also because population is struggling for more higher life standards, that requires costs, also in energy consumption raise, per capita! Specialists consider fossil fuels in a hopeless long term struggle with a renewable energy steamroller that are in their majority sustained by the states or direct by the population, in not always very fair financial schemes.

The answer to the question is: No, only with fossil fuels alone as resource no sustainable future can be built. Renewables and especially bio-energy must complete a stable mix offered to the market, and turn, after a transition period, specific to the development and political will of the countries, in majority, or even to $100 \%$ cover of the necessities (industrial, transport, house holding, social, etc.). The paper will highlight the advantages of the fossil fuels ( $\mathrm{C}$ based and presently abundant but fundamentally limited resource), the possibility of their sustainable implementation, in parallel the disadvantages and correspondingly the disadvantages and advantages of the renewable sources. But man mind is active and thus the world will be kept as a functional eco-system also in the next future, and forever!
\end{abstract}

Keywords: climate change, fossil fuels, renewable energy, $\mathrm{CO}_{2}, \mathrm{C}$ based economy

\section{Introduction}

Even if one is ignoring the $\mathrm{CO} 2$ generated global climate change problems, fossil fuels are limited in the amount Earth contains and also extracting, and transporting, refining and burning them cause large amounts of pollution [1]. The burning of fossil fuels generates pollution, since these carbonbased fuel sources contain a lot more than just carbon and hydrogen in their chemical makeup, and using the in exothermal reactions (to generate energy) also generate all the impurities, namely pollutants, so much blamed today for the outdoor pollution of air, and not only, releasing them into the air. In addition, the refining and/or extraction process is dirty, dangerous and can pollute the water table and entire bodies of water, like rivers and lakes $[1,2]$.
Figures 1 and 2 bring an example with results of regularly accomplished measurements of air quality by two station in urban areas, which are characterized by industry, traffic and the result of urban island polluting effects, including house holding. The two labs, that are measuring simultaneously proof, that the air quality is fluctuant along the day and night time, mostly in close connection to the traffic intensity. Such regularly campaigns are compulsory to be carried out by the Ministry of environment (of a specific country, in the example in Romania). The second lab is accredited (www.mediu.ro) by the national body (RENAR). Figure 3 brings a view of the stations used for monitoring [3,4]. The amount of pollutant emitted during a particular activity depends on the intensity of that activity, the principle underlying the use of emission coefficients or factors. Thus, for a particular economic sector, the output of 
emissions into the air is proportional to the output produced. Choosing an emission factor depends on a number of factors such as: the technology used to obtain the product, the nature of the fuel, state of art of the technology applied, the national production conditions, etc

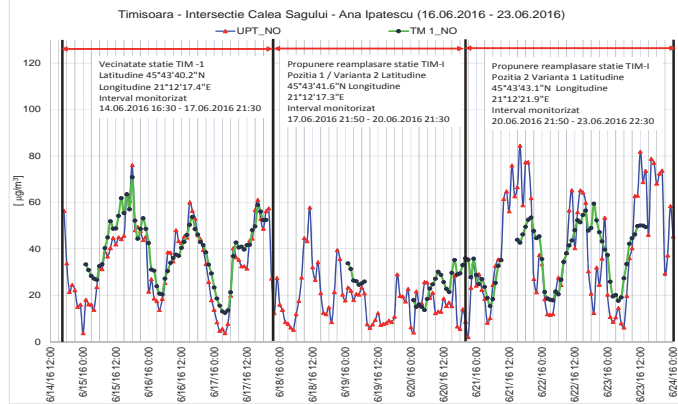

Figure 1. Example of on line monitoring in urban area, taking into account two laboratories, one of the ministry of environment and one accredited for such purposes.

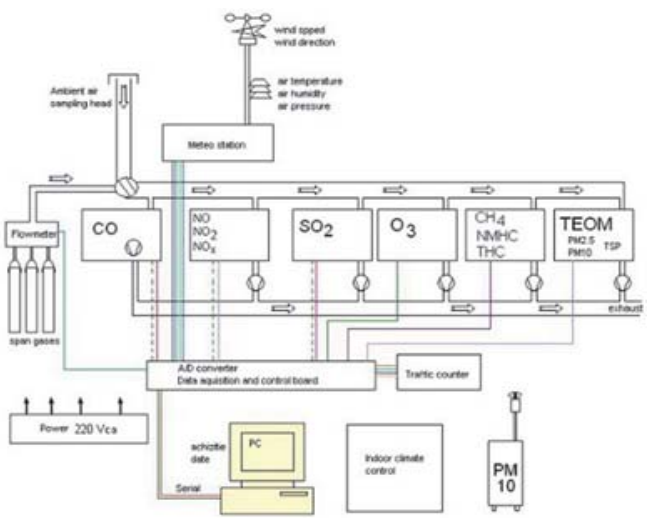

Figure 2. Example of the lab LACIEDIN of the Politehnica University of Timisoara (www.mediu.ro) [3, 4].

. Emission sources are characterized mostly. by the type of activity and type of the fuels used.Generally speaking, the formula used is [5]:

$E_{i, j}=A_{i, j} \times E F_{i, j}$

where: $\mathrm{E}$ is the emissions' source;

A - intensity of the activity;

$\mathrm{EF}$ - emission factor;

$\mathrm{i}, \mathrm{j}$ - pollutant and activity.

This formula assumes that there is a technical link between the activity intensity (A) and the emission (E). The formula shows that if the rate activity increases by $20 \%$, then the emission increases by $20 \%$ (if the factor emission remains constant). At the level of economic operators this relationship is not always valid, but for national global calculation, the formula provides a sufficient degree of accuracy [5]. Thus it is obvious that if the tendency of developing needs more and more energy (heat and electricity generated through classic forms non-renewable, based on fossil fuels and combustion processes) and transport (even electric ones or hybrid) and, if these sources are even controlled and reduced in the emissions' output by technological removal processes, the pollution will increase, by the level of energy consumption augmentation

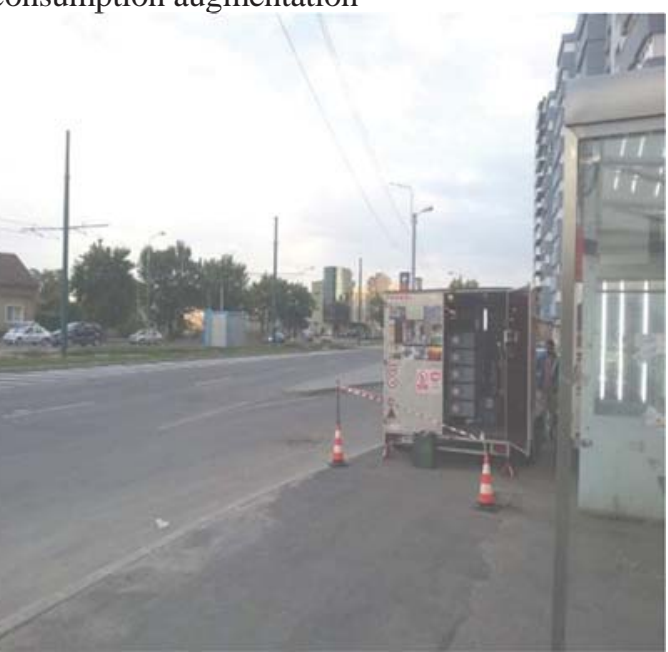

Figure3. Location of both laboratories for on line monitoring of air quality in Timisoara city.

Segments can be defined at different levels of detail or aggregation, from case to case.

Activity rate is generally the result of (i) relevant scenarios for a specific sector (value-added) or (ii) may be based on a general scenario economic depending on the level of aggregation. The emission factor (EF) is a technological parameter by which the broadcasting potential of an activity in a direct relationship with the type is established fuel used in the combustion process or process processing with raw material. A central feature of the energy transition mapped out by the presentation is the continued gradual decarbonization of the fuel mix.

\section{Decarbonisation}

\section{General}

Since the Paris COP 21 by 2015, Climate Changes policies are guided by the Sustainable 
Development spirit as a general concept \& commitment. A central feature of the energy transition is the continued gradual decarbonization of the fuel mix. If one looks at the still available fossil fuel resources, the real crisis might not be their limited availability, but the amount of climate change inducing greenhouses gases embedded in the known reserves [6]. If the humanity wants, as agreed internationally, to limit the global warming to 2 degrees (based on preindustrial climate status), $80 \%$ of the world's known reserves of coal, $50 \%$ natural gas and $30 \%$ of oil need to stay in the ground. The amount of greenhouse gases embedded in the currently known reserves exceeds the remaining carbon budget by three times [6].

Rapid improvements in the competitiveness of renewable energy mean that increases in renewable sources, together with nuclear and hydro energy, provide around half of the increase in global energy out to 2035 [7]. Natural gas is expected to grow faster than oil or coal, helped by the rapid growth of liquefied natural gas increasing the accessibility of gas across the globe [7]. Figures 4 and 5 indicates the history and tendency in the population grows (that is the key factor for the energy growth consumption). Also they show that the energy intensity is subject of severe reduction, as technology advanced.

Figure 6 gives the profile of the primary energy sources, by type, including both fossil and renewable sources [7]. Clean energy sources may pollute a lot during their technological process of creating the facilities to exploit them. Example the electric cars. They reduce the amount of pollution in cities, but the locations, where the batteries are produced or deposit as waste, are very affected!! Such sources contribute to local reduction of pollution, meaning shifting the pollution from one place to another. On our opinion totally non polluting clean sources do not exist! For every source one has to pay a price "with the environment destruction".
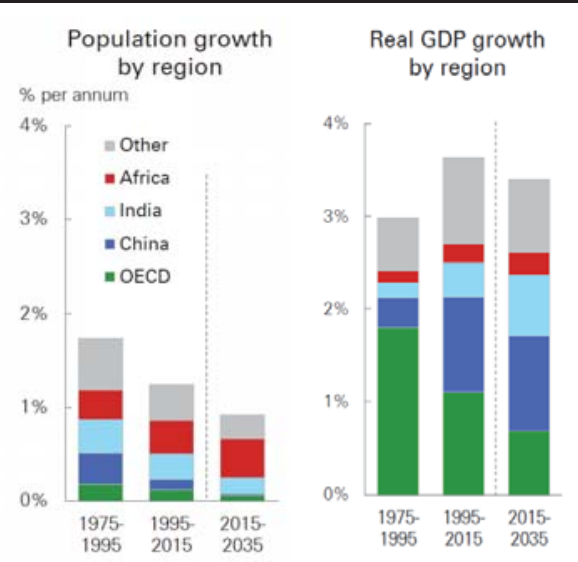

Figure 4. Population and GDP augmentation, by regions [7].

\section{Growth in GDP and primary energy}

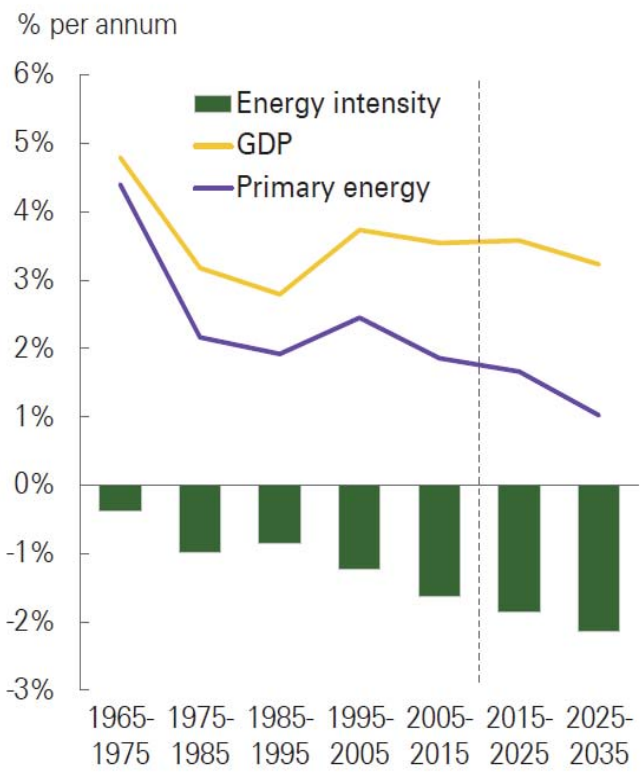

Figure 5. Growth in GDP and primary energy [7].

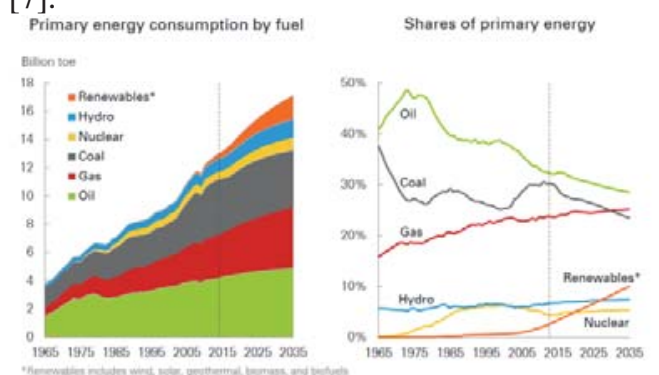

Figure 6. Primary energy sources [7]. 


\section{Costs}

Due to the declining costs of solar and wind technologies as well as the anticipation of a more carbon-constrained future, today the global growth of renewable energy is increasingly driven by voluntary procurement by utilities and corporations [6]. Solar energy, as recently proved [8] is affected trough the air pollution, and thus the efficiency of the equipment can be reduced. Biodiesel is considered [10] one promising energy source. Many believe that this alternative source of energy will be able to sustain the need for increased energy security while at the same time being friendly to the environment [9].

Green tariff programs are one example of how utilities are adapting to this growing consumer demand to choose their energy supply. It is still a major support from the end users, and this is not totally correct, as the effects of using renewable sources are global, not mentioning social aspects, by transforming the classic specialists into a new branch and era of professionals. In recent years, Renewables effectively competed against fossil fuel generation in power markets and for procurement contracts around the world [6].

Renewable energy markets matured these days, on both a global (industrial, energy producers) and domestic scale, through more competition and resource diversity [6]. A very important phenomenon occurs more and more often:

Many companies produce their own energy from own technological waste (Waste to energy concept)! Thus a lot of industrial energy consumer turn into energy producer as well, majority for own use.

Different sources of energy produce different amounts of heat-trapping gases are revealed by Figure 7. Renewable energies tend to have much lower emissions than other sources, such as natural gas or coal.

The expected slowdown in carbon emissions growth reflects significant increases in the decline in energy intensity and in the change in the fuel mix, characterized by coal consumption slowing sharply and gas - together with Renewables, nuclear and hydroelectric power supplying almost $80 \%$ of the increase in energy [6].

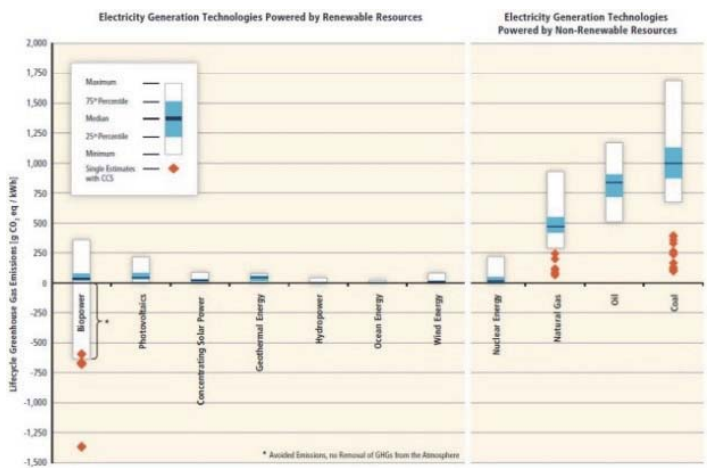

Figure 7. Comparison of different sources, in concern to $\mathrm{CO}_{2}$ equivalent emissions [10].

\section{Contributions to slower growth of carbon emissions}

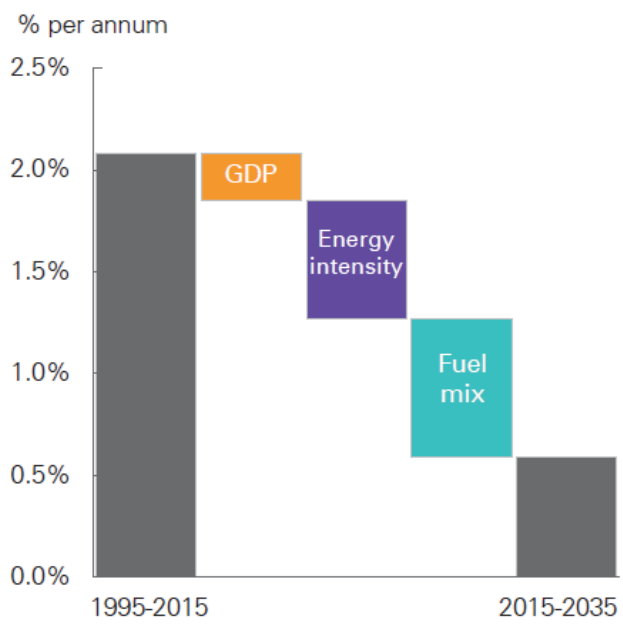

Figure 8. Contribution of essential factors to slow down the $\mathrm{CO}_{2}$ emission [6].

Figure $9[6]$ is completed according data offered from different major energy international organisation:

IEA: International Energy Agency, World Energy Outlook 2016 , Paris, France, November 2016,

EIA: US Energy Information Administration, International Energy Outlook 2016, Washington, D.C., United States, May 2016, MIT: MIT Joint Program on the Science and Policy of Global Change, 2016 Food, Water, Energy and Climate Outlook, Cambridge, MA, United States, 2016, 
IEEJ: Institute of Energy Economics Japan, Asia/World Energy Outlook 2016, Tokyo, Japan, October 2016,

IHS: IHS Energy, Rivalry: the IHS Planning Scenario, July 2016,

PIRA: PIRA Energy Group, Scenario Planning Guidebook, Appendix, February 2016,

XOM: ExxonMobil, 2017 Outlook for Energy:

A View to 2040, December 2016,

CNPC: CNPC Economics \& Technology

Research Institute, Energy Outlook 2050, 2016,

Greenpeace, Energy Revolution, September 2015,

BP p.l.c., BP Statistical Review of World Energy, London, United Kingdom, June 2016, International Energy Agency, Energy Balances of Non-OECD Countries, Paris, France, 2016, International Energy Agency, Energy Balances of OECD Countries, Paris, France, 2016,

UN Population Division, World Population Prospects: The 2015 Revision, New York, United States, 2016.

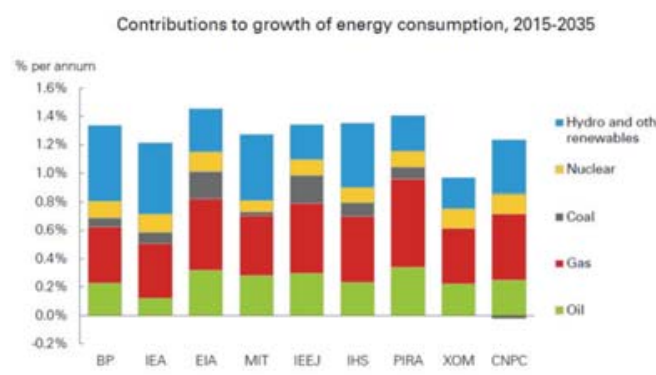

Figure 9. Fuel mix prognosis and data recorded [6].

According to [11], wind and photovoltaic capacities have been lately massively developed in Romania. Although they have already made an important contribution to Romania's target of reducing GHG emissions for 2020, decreasing the average wholesale price of electricity and decreasing import dependency, their intermittent nature has caused technical difficulties and costs of integration into National Power System, as well as an impact on the final consumers' bill.

The expected slowdown in carbon emissions growth reflects significant increases in the pace of decline in energy intensity and in the pace of change in the fuel mix, with coal consumption slowing sharply and gas - together with Renewables, nuclear and hydroelectric power supplying almost $80 \%$ of the increase in energy. The need for a fair and accurate calculation of the $\mathrm{CO}_{2} / \mathrm{kWh}$ (electric, heat) rate is a necessity and must summarize not only the direct exhausted $\mathrm{CO} 2$, but also the $\mathrm{CO} 2$ emission associated to the production of equipments, organising and retrofitting the plant, etc. Social aspects must also be taken into consideration, here not only employment aspects, but also costs of the energy generated, access to a secure and healthy energy, assuring sustainable development being a key ssue as well.

\section{Conclusion}

Only those energy policies that are able to limit the Climate Change impact on our societies must be developed.

Thus one do not exclude fossil fuels, nuclear energy sources etc, if the improoved technologies, such as CCS and clean technologies are adopted. For the present generation, the question is not to face a lack of resources, but to aply clean/green energy.

Photovoltaic, or Wind, Biomass (Bio-energy), Solar Energy offer a huge potential of magnitude higher that the present $t_{\text {annual }}$ world energy demand (about 13000 MTOE). No risk to run out of energy!

Acknowledgment

The article is based on literature recherché of the authors', aa part of the accredited lab LACIEDIN of the Politehnica University of Timisoara, as well as PhD student (last author).

This article has received scientific support also from the ACTRIS project, funded from the European Union's Horizon 2020 research and innovation programme under grant agreement No

654109

[http://www.actris.eu/Outreach/Publications/Gu idelinesforpublishingandreporting.aspx].

\section{References}

Et. Siegel, The Future of Energy isn't fossil fuels or renewables, it's nuclear fusion, https://www.forbes.com/sites/startswithabang/2 017/04/12/the-future-of-energy-isnt-fossilfuels-or-renewables-its-nuclearfusion/\#a703f133beeb, accessed February 2017. https://www.forbes.com/sites/startswithabang/2 
017/04/12/the-future-of-energy-isnt-fossil-

fuels-or-

renewablesitsnuclearfusion/\#a703f133beeb.

[3] I. Ionel et all, Air Quality, editor Ashok

Kumar, InTech, Chapter 5 Methods for on line monitoring of air pollution concentrations, https://www.intechopen.com/books/air-

quality/methods-for-online-monitoring-of-airpollution-concentration, DOI 10.5772/9754, accessed May 2017.

I. Ionel et all, From theory to practice concerning air quality monitoring, AIP Conference Proceedings 1796, 040002 (2017); online: https://doi.org/10.1063/1.4972380 Published by the American Institute of Physics.

Mihăiescu, R., Monitoringul integrat al mediului, Cluj Napoca, 2014, pp. 87-88, http://enviro.ubbcluj.ro/studenti/cursuri\%20sup ort/Carte_Monitoring_Radu_SITE.pdf.

Ch. McGlade, P. Etkins, The geographical distribution of fossil fuels unused when limiting global warming to $2{ }^{\circ} \mathrm{C}$, Nature $517,187-$ 190 (08 January 2015), doi:10.1038/nature14016.

BP Energy Outlook, 2017 edition, www://bp.com/energyoutlook \#BPstats.

Outlook on renewable energy My take: Marlene Motyka , Deloitte Centre for Energy solutions, 2017 , https://www2.deloitte.com/ content/dam/Deloitte/us/Documents/energyresources/us-er-renewable-energy-industryoutlook.pdf.

D.G. Calinoiu, Cercetări privind influența aerosolilor asupra potenţialului energetic solar prin investigarea transferului radiativ în atmosferă (Research on the influence of aerosols on the solar energy potential through investigation radiation transfer into the atmosphere), $\mathrm{PhD}$ Thesis, Politehnica Publishing House, 2012.

H. Hashim, ～Z. Mahadi, M.Ibrahim and KIsmail, Determinants of stakeholders' attitudes towards biodiesel, Biotechnology for Biofuels201710:219, https://doi.org/10.1186/s13068-017-0908-8.

Intergovernmental Panel on Climate Change (IPCC). 2011. IPCC Special Report on Renewable Energy Sources and Climate Change Mitigation. Prepared by Working Group III of the Intergovernmental Panel on Climate Change [O. Edenhofer, R. Pichs-Madruga, Y. Sokona, K. Seyboth, P. Matschoss, S. Kadner, T.
Zwickel, P. Eickemeier, G. Hansen, S. Schlömer, C. von Stechow (eds)]. Cambridge University Press, Cambridge, United Kingdom and New York, NY, USA, pp. 1075 pp. (Chapter 9).

R. Nicoloiu, I. Ionel, I. Voda,The Evolution of Green Certificate Support Scheme for Promoting Renewable Energy in Romania, 9781-5386-3943-6/17/\$31.00 @2017 IEEE. 